\title{
Diferenciação e sustentabilidade a partir do redesign de roupas de brechó: um modelo de estratégia produtiva
}

Differentiation and sustainability from flea clothing for redesign: a strategy model production

Nádia Estefânia de Souza Bacharel em Design de Moda UEL nadiless@hotmail.com

Lucimar de Fátima Bilmaia Emidio

Mestrado em Desenho Industrial - UNESP lucimaremidio@gmail.com 


\section{Diferenciação e sustentabilidade a partir do redesign de roupas de brechó: um modelo de estratégia produtiva \\ Differentiation and sustainability from flea clothing for redesign: a strategy model production}

\section{Nádia Estefânia de Souza e Lucimar de Fátima Bilmaia Emidio}

\section{Resumo}

Pautado em pesquisa bibliográfica e de campo, e em estudo de casos, o presente trabalho apresenta uma reflexão em torno de um modelo de processo produtivo na área do design de moda focado na sustentabilidade. Trata-se de uma proposta metodológica que contempla o redesign de roupas de brechó, descartadas e desvalorizadas por se encontrarem fora das tendências de moda, que poderão passar por um processo de upcycling, estendendo seu ciclo de vida útil e voltando a ter valor estético e de mercado. Objetiva-se mesmo que, numa pequena parcela, contribuir com o meio ambiente de forma criativa e inovadora, tendo como diferencial o fato de possibilitar a reprodução das peças em escala, sem perder a exclusividade.

Palavras- chave: redesign de roupa de brechó; sustentabilidade; moda e consumo.

\begin{abstract}
Guided by bibliographical and field research, and case studies, this paper presents a reflection around a production process model in fashion design area focused on sustainability. It is a methodology that includes the redesign of thrift store clothes, discarded and devalued because they are out of fashion trends, which may undergo a upcycling process, extending its life cycle and turning to have aesthetic value and Marketplace. The objective is even in a small part, contribute to the environment in a creative and innovative way, with the difference the fact of enabling the reproduction of parts in scale without losing the exclusivity.
\end{abstract}

Keywords: redesign of thrift store clothes; sustainability; fashion and consumption. 


\section{Introdução}

O mundo da moda tem sofrido transformações em decorrência de novos hábitos de consumo, assim como pela forma que a indústria da moda tem correspondido a essa nova demanda. A criação sazonal, de duas coleções anuais do prêt-à-porter, já não é suficiente para acompanhar o surgimento de novas tendências, fator que têm sido cada vez mais presente devido ao a facilidade de acesso à informação de moda globalizada pelo consumidor.

A necessidade de novidades é cada vez mais saciada e instigada principalmente pelas cadeias de fast fashion ${ }^{1}$ com lançamentos de inúmeras coleções ao ano. Estes produtos têm preços relativamente baixos, e muitas vezes seguem tendências de moda que na mesma velocidade em que surgem, desaparecem, sendo logo descartados e substituídos pela mais nova tendência do momento.

De forma sintética, segundo Lipovetsky tem-se de um lado um público com vontade de consumir inovações efêmeras e, do outro lado, o mundo da moda suprindo essa necessidade, colocando à disposição de seus consumidores inovações, destacando sempre o novo e incentivando a deixar de lado o que já passou.

Com o atual consumo desenfreado, os produtos de moda podem até mesmo ser considerados descartáveis. Somente a nível nacional, segundo dados apresentados pelo governo no site do Ministério do Desenvolvimento, Indústria e Comércio Exterior, no ano de 2013 a produção anual de produtos de vestuário é de 9,8 bilhões de peças, o que significa aproximadamente 50 peças anuais por consumidor, considerando que toda a população tenha o mesmo padrão de consumo, o que é sabido não ser um dado exato devido à grande desigualdade social brasileira.

A necessidade do consumidor de possuir as novas tendências, e a rápida resposta das indústrias de moda a esse desejo acabaram tornando o consumo banal e descontrolado.

O planeta está sofrendo com esse estilo de vida, e não sustentará esse consumo desmedido por muito tempo. A produção industrial em geral causa muita poluição, assim como desordem climática. Logo, seria de grande ajuda ao meio ambiente se as roupas tivessem um ciclo de vida prolongado, diminuindo a produção gerada pela demanda causada por esse consumo desmedido.

\footnotetext{
${ }^{1}$ Termo utilizado para denominar o sistema de marcas que possuem uma política de produção rápida.
} 
Com base neste contexto, o presente estudo pautado em pesquisa bibliográfica, estudo de casos, e pesquisa de campo apresenta uma proposta de novos destinos para as roupas, que por estarem fora das tendências de moda, acabam esquecidas em brechós ou bazares beneficentes. Para que essas peças voltem a ter utilidade e valor estético, a alternativa aqui disseminada, é aplicação do redesign, por meio do processo de desconstruir e reconstruir, de forma que continuem a acompanhar a moda, sem fugir das demandas do mercado atual.

Além disso, contempla-se a importância da reprodução das mesmas, porém, sem perder a característica de diferenciação que geralmente o público que compra em brechós leva muito em consideração.

\section{O CONSUMO NA ATUALIDADE E SEU FUTURO}

De acordo com Lipovetsky e Serroy, o mundo está caminhando para uma globalização que será definida como cultura-mundo, onde cultura deixará de ter o sentido "culto" e passará a ser popular, uma cultura global. As gerações se tornarão simplesmente cidadãos do mundo, com uma identidade global. Desta forma, surgirão consumidores saturados da mesmice causada por essa generalização cultural, buscando se individualizar dentro de uma sociedade que será homogênea.

A partir desta reflexão, infere-se que assim como os cidadãos serão muito semelhantes, os hábitos de consumo também serão. E de igual forma, alguns consumidores cansados da moda globalizada buscarão se diferenciar por meio de suas escolhas. Este consumidor buscará saber a procedência de cada peça que comprar, o que fará com que a indústria se adapte e os produtos sejam concebidos para durar mais e resistir a mais de uma estação, seguindo a tendência Slow Fashion ${ }^{2}$.

Segundo Bezerra, Matos e Pessoa, os designers deverão se adaptar, buscando novas tecnologias para que os produtos tenham uma maior durabilidade e pensando em novas formas nas quais o produto que criar provoque o menor impacto ambiental possível. Assim, o designer passará a trabalhar em um novo cenário imposto tanto pelo meio ambiente, quanto pelos novos hábitos da sociedade.

O jornal britânico The Guardian, do mês de Julho de 2008, destaca um novo estilo de consumo, mais consciente, e juntamente com ele a moda ética, com princípios

\footnotetext{
${ }^{2}$ Movimento de moda sustentável que defende o consumo consciente e condena a efemeridade da moda.
} 
éticos e sustentáveis. Este tipo de moda se contrapõe ao fast fashion, um modelo de negócio por meio do qual os produtos tem alta rotatividade, e seus bordões desesperados por persuadir o consumidor a comprar compulsivamente as novas tendências que surgem quase que diariamente.

A moda ética é contra a produção escrava, roupas de baixa qualidade, comprar e descartar peças compulsivamente, e a favor de salários justos, uso de materiais ecologicamente corretos e uma produção que se preocupe com o impacto ambiental que pode causar.

E assim, as marcas vão se adaptando, inserindo pouco a pouco uma peça ou outra produzida de forma ecologicamente correta. Essa parcela de marcas que estão contemplando a moda ética ainda é pequena, mas acredita-se que essas estão dando o início para que outras as acompanhem, considerando essa nova modalidade de consumo.

Mesmo que essa proporção da indústria a contemplar os princípios éticos de produção seja pequena, a diferença que fará para o meio ambiente e bem estar dos colaboradores desse ramo serão satisfatórios. Assim como, se os consumidores mudarem, mesmo que lentamente, seus hábitos de consumo, será um incentivo para que a indústria busque contemplar os princípios éticos.

As matérias publicadas no Jornal The Guardian no ano de 2008, mostraram ainda que os britânicos já estavam colocando em prática uma nova forma de consumo, buscando roupas com matérias-primas mais duráveis, de indústrias das quais os produtos são autênticas, com boa qualidade, e que não há exploração de mão de obra.

No Brasil ainda há falta de informação por parte do consumidor em relação ao consumo consciente, mas existem empresas nacionais contribuindo com este cenário, por meio da criação de roupas com maior ciclo de vida, além de utilizarem de matérias primas que causem menos impactos ambientais, entre outros.

\section{FAST FASHION X SLOW FASHION}

A busca incessante pelo novo, e o desejo de consumo incentivaram a criação de um modelo de negócios conhecido como Fast Fashion. Os produtos desenvolvidos a partir deste modelo tem uma alta rotatividade, sendo lançados diversas vezes durante o ano, fugindo do costumeiro lançamento sazonal de coleções. Segundo Erner, este estilo 
iniciou-se com lojas de departamento como Zara, $H \& M$, TopShop e se difundiu pelo mundo.

Os produtos oriundos da indústria Fast Fashion agradam com o valor agregado pelo design e a velocidade com que se encontram disponíveis no mercado, satisfazendo as necessidades momentâneas do consumidor, não se importando com a qualidade e durabilidade dos produtos.

O problema deste modelo de produção é, sobretudo, a efemeridade dos produtos. Como o consumidor quer sempre as últimas novidades da moda à disposição, e muito rapidamente são lançadas novas tendências, a busca pelo novo e descarte do antigo é um processo muito rápido, o que faz com que a indústria tenha um volume de produção muito grande para suprir essa necessidade de novidades.

A produção de artigos de vestuário, em sua maioria causa poluição e têm sérios impactos ambientais, dentre os quais Neto, Souza e Scapinello destacam: problemas com a água (devido ao beneficiamento e tingimento dos materiais); problemas atmosféricos (as indústrias têxteis geralmente lançam ao ar grandes quantidades de gases poluentes, como dióxido de carbono e metano); problemas no solo (os resíduos sólidos ocasionam prejuízos à natureza, assim como infiltração de águas contaminadas); aquecimento global (a produção de materiais demanda uma grande quantidade de energia e gera muito calor, o que eliminará o sistema de condicionamento natural).

Diante desse cenário, surge um modelo de produção, que busca produzir moderadamente e aposta em produtos com maior qualidade, durabilidade e estética que foge de modismos passageiros. É a antítese do Fast Fashion, o chamado Slow Fashion.

Este modelo tem chamado atenção em várias partes do mundo. Em 2002, surgiu no Japão um movimento chamado "Slow Life", propondo um estilo de vida comedido. Este surgiu como uma reação ao estilo de vida dominante baseado no consumo desmedido e na despreocupação quanto aos valores sociais e ecológicos. A partir deste movimento surgiu o "slow wear", que busca a moda de forma perene, com valores sociais, ambientas e econômicos de forma sustentável, afirma Carneiro et al.

Stone cita o trabalho dos designers Uruguaios, Ana Livni e Fernando Scuder, como adeptos e defensores do movimento Slow Fashion. Na página inicial do site da marca da dupla, "Ana Livni”, destaca que seu trabalho é resumido em "trabalhar sem pressa, sem pausa, conhecendo cada etapa do processo. Traçar um projeto de design em 
permanente construção".

Estes designers criaram uma filosofia para o movimento Slow Fashion, o "Manifesto Moda Lenta Slow Fashion", onde propagam a sustentabilidade, consciência e respeito, exaltando a importância da produção sustentável, do acompanhamento do ciclo do produto e sua relação com a terra. O tópico três do movimento chama atenção para a velocidade da produção em relação a qualidade do produto: “Atitude sem pressa não significa fazer menos, nem ter menor produtividade, e sim, significa trabalhar em busca de uma melhor produtividade, superando a qualidade com criatividade."

A Slow Fashion é uma manifestação que atinge a mentalidade do consumidor que busca um conceito por trás do produto, busca algo que transcenda sua beleza estética.

Um fator que pode ser um empecilho para que este tipo de produto conquiste mais adeptos é seu custo final. O ritmo de produção e a quantidade de produtos produzidos, se comparado com os produtos em larga escala, é menor, o que eleva o custo e acaba em desvantagem em relação aos produtos do sistema Fast Fashion.

Daí a importância do profissional designer atuar com propostas, que contenham princípios sustentáveis, emocionais e que sejam economicamente acessíveis.

\section{A METODOLOGIA E OS PARÂMETROS ANALISADOS}

A história mostra que foi a partir dos anos 90 que o público europeu passou a apreciar os produtos de vestuário de épocas diferentes, propagando por todo o mundo. No Brasil, foi há pouco mais de uma década que os brechós se tornaram populares. Estes têm se apresentado como uma ótima alternativa para o público que não busca estar na moda, mas acima de tudo fazer sua própria moda, com exclusividade, modernidade, de forma acessível e consciente.

Pelo perfil e característica do trabalho, além de utilizar do delineamento bibliográfico, análise de casos, realizou-se também uma pesquisa de público, utilizandose de questionário visando identificar a existência de público que se encaixa nesta abordagem. Esta foi realizada virtualmente no site de relacionamentos Facebook, e divulgada especificamente a um grupo de compra, venda e troca de "produtos de segunda mão", onde as pessoas apreciam e tem o hábito de frequentar brechós físicos. A pesquisa obteve 80 respostas em duas semanas. 
Buscou-se identificar a faixa etária, características socioeconômicas, psicológicas, hábitos de consumo, além de especificamente investigar o que as leva a comprar em brechós, e sua opinião acerca da qualidade das peças. O resultado deste levantamento foi fundamental para a delimitação da proposta apresentada na sequência deste trabalho.

Além destas, optou-se também por realizar uma pesquisa de campo junto à aproximadamente 10 brechós na área central da cidade de Londrina, onde há uma grande concentração de lojas desse segmento, visando conhecer a realidade destes, bem como as peças lá disponíveis.

Posteriormente, este levantamento se estendeu à cidade de Londres, na Inglaterra, com o objetivo de conhecer a realidade do comércio de segunda mão de roupas em uma cultura diferente e averiguar a possibilidade da aplicação da proposta a nível mundial.

Segundo Carter na matéria “Why fast fashion is so last season" publicada no jornal britânico The Guardian, o Reino Unido possui uma lista com mais de 200 lojas que buscam promover a moda ética. Outra forte característica da cidade de Londres é possuir muitos bairros que abrigam diversas vintage stores, lojas que comercializam produtos de segunda mão, como brechós tradicionais, mas especializadas em peças vintage.

Desta forma, foram pesquisados dez brechós de Londrina e o mesmo número de vintags storesde Londres. Acerca deste comércio na cidade de Londrina, conforme o levantamento realizado pela autora, existem cerca de 50 brechós em vários bairros da cidade, além de bazares beneficentes.

Nos brechós, geralmente as peças são mais selecionadas, buscando estar de acordo com as tendências de moda do momento, mas sempre há peças que não atendem essa exigência e acabam demorando mais para serem vendidas.

$\mathrm{Na}$ análise feita em brechós situados na região central, os modelos encontrados em maior variedade foram: saias lápis, camisas tradicionais (tanto femininas, quanto masculinas), blazers, vestidos longuetes sem detalhes, calças jeans e calças sociais femininas e masculinas.

Já os bazares beneficentes recebem peças por intermédio de doações de benfeitores, portanto, há uma variedade grande de modelos, mas não são selecionados. 
Há um acúmulo de peças de diversos tamanhos, modelos e estilos, mas as que estão em maior número, assim como nos brechós, são camisas (femininas e masculinas), calças jeans e blazers.

Identificou-se que há preconceito por parte dos consumidores em relação aos brechós, devido ao seu aspecto antigo, muitas vezes cheirando a mofo, e sua aparência desorganizada com peças abarrotadas. Em contrapartida, há um público que se identifica e tem muito apreço por este tipo de mercado. Esse público vê os brechós como uma opção de consumo, como algo moderno. As roupas de segunda mão, que antes eram apenas roupas para caridade, hoje tem valor emocional, com características simbólicas e subjetivas.

Em uma pesquisa etnográfica citada no artigo "Significados Culturais das Roupas de Segunda Mão de um Brechó”, realizada em um brechó de Luxo do Rio de Janeiro, pôde-se enumerar os seguintes valores que as peças têm para os clientes: desejo de exclusividade e diferenciação perante a massa; qualidade (no caso dos brechós de luxo as peças se encontram em ótimo estado de conservação); reciclagem; transcendência (no sentido desse bem ser algo imortal, ou seja, vai durar para além da vida de seu dono); compra inteligente, devido ao preço inferior em relação às peças novas; moda (comprar em brechó está "na moda"); apesar de ser de segunda mão, tem aparência de novo (e mesmo que o produto já tenha sido de alguém, para quem está comprando, este produto é novidade).

Salienta-se que a diferença entre os brechós pesquisados em Londrina, interior do estado do Paraná, em relação aos brechós de Londres, capital inglesa é muito expressiva. Os brechós de Londrina, em sua grande maioria, buscam roupas que acompanhem as tendências atuais, e os preços das peças de "segunda mão" são muito inferiores aos de roupas novas, além da conservação e organização das roupas deixarem muito a desejar.

Já nos brechós de Londres, cidade é reconhecida mundialmente pelos brechós com uma grande riqueza histórica, são encontradas peças realmente antigas, com seu design original conservado e muito valorizado. Os preços das roupas nos brechós da capital inglesa são superiores aos de roupas novas em lojas de departamento.

Pode-se considerar que essa diferença está na cultura e no valor que cada lugar dá à história da moda. $\mathrm{O}$ público que busca esse tipo de comércio em Londrina é muito 
diferente daqueles que o aprecia em Londres. Os londrinos que dirigem-se as vintage stores, buscam peças com valor histórico e emocional.

Desta forma, concluiu-se que a aplicação da proposta possui um maior significado no cenário londrinense, pois as peças encontradas nos brechós londrinos já possuem um grande valor para o seu público na exata forma como se encontra, logo não necessitam de redesign.

\section{O REDESIGN NA FORMA DE DESCONSTRUIR PARA RECONSTRUIR E O UPYCLING: ANÁLISE DE CASOS}

Brezet e Rocha esclarecem que no processo de redesign, o conceito do produto continua o mesmo, porém os seus componentes são melhorados de acordo com critérios, como: utilizar materiais não tóxicos; considerar o uso de materiais reciclados e recicláveis; facilitar a desmontagem do produto; o reuso dos componentes; a redução de energia, entre outros.

Apresenta-se a seguir o contexto de três casos, cuja análise dos mesmos contribuiu para a proposição do modelo de estratégia produtiva, resultante do estudo.

1) Trata-se do artigo disseminado por Giuratti, Berton e Pinheiro intitulado: "Revival e diferenciação como diretrizes da moda contemporânea: a elaboração de produtos de moda a partir da reciclagem de roupas de brechó". Neste, apresenta-se um trabalho em que consistiu na utilização de roupas de brechó para, a partir do recurso de desconstrução e reconstrução, construir um discurso estético atual, assim como compor looks com roupas de mais de vinte anos de história, sem alterações, proporcionando um estilo único.

Deste projeto, destacou-se para este estudo a primeira proposta, na qual o objetivo era desconstruir roupas antigas e reconstruí-las de acordo com uma linguagem contemporânea. Eles realizaram uma pesquisa exploratória para se familiarizar com o fenômeno a ser investigado, além de utilizar-se também de estudos de caso.

Inicialmente, os autores possuíam as seguintes peças: um blazer, uma camisa, um vestido e um retalho de tecido florido. A partir da união do blazer com a camisa, criaram um vestido estilo chemisier. Com o vestido sem detalhes e o retalho de tecido florido, além de um outro tecido com aparência sedosa, concebeu-se um vestido longo de manga longa. Ambas as peças ficaram atuais, mas sem perder a diferenciação que 
este tipo de peça deve ter.

2) Aborda uma proposição de PSS (sistema produto-serviço), apresentada no artigo intitulado: "Moda e Sustentabilidade: proposta de sistema produto-serviço para Setor de Vestuário”, de Martins, Sampaio e Mello. O objetivo do referido trabalho foi propor um PSS para ser aplicado em uma empresa da cidade de Londrina PR, visando evitar o desperdício de materiais e reaproveitar a matéria prima já utilizada e comercializada, antes de ser descartada de forma indevida, mas sem desconsiderar os aspectos econômicos, como a redução de gastos com recursos e a criação de diferencial competitivo.

Na referida publicação, é apresentado os resultados deste projeto prático, que consta na criação de uma segunda linha de produtos para a empresa, de cunho ecologicamente correto e sustentável, a partir do re-design de peças da própria marca, já usadas e descartadas pelos clientes.

Essas peças eram recolhidos em um posto de coleta, e depois encaminhados para passar pelas seguintes etapas: 1) sistema de recolhimento; 2) avaliação das condições das peças; 3)estudo de modelagem/ desconstrução; 4) banco de tecidos e de aviamentos; 5) estudo de viabilidade/ redesign; 6) re-modelagem/ produção; 7) marketing. Neste caso citado, sobressaiu para este estudo o sistema pelo qual as peças usadas passaram, foram remodeladas e atualizadas, conforme descrito a seguir:

Inicialmente, o departamento de modelagem desconstrói uma peça de cada modelo recolhido, a estuda e envia as informações para o setor de criação; o restante das peças deste modelo são desconstruídas, reservadas e quantificadas, depois enviadas para que o setor de PCP (planejamento e controle de produção) tenha controle dos materiais disponíveis para ser usado posteriormente.

Durante o processo de redesign, o responsável pelo departamento de criação, juntamente com sua equipe, analisa as novas possibilidades de construção e interferências, conferindo um diferente aspecto e uma nova referência à coleção. Para cada peça recolhida, surgirão no mínimo, três peças novas como opção. Depois da geração de alternativas, designer e delista analisam a viabilidade da produção de cada peça, dando preferência para a que obtenha a menor economia de material, maior aproveitamento de aviamentos, menos interferências têxteis e menor tempo de produção. 
Desta forma, a empresa conseguiu obter sucesso nesse processo de trabalho permitindo que peças antigas, depois de passarem por todo um processo de redesign, adquirissem um aspecto atual, ampliando seu ciclo de vida e evitando que as mesmas fossem descartadas, tendo como fim o meio ambiente.

3) O upcycling como alternativa sustentável na área da moda: semelhante ao redesign, surge upcycling, um novo conceito sustentável que se destaca, principalmente nas áreas do design. É segundo Anicet, Bessa e Broega um processo de reutilização que busca transformar os resíduos desperdiçados em novos produtos com qualidade superior, além de agregar valor ambiental ao mesmo. Caracteriza-se por se utilizar de um material já utilizado, ou resíduos de produtos com menos consumo de energia na reutilização do mesmo, sem ter a necessidade de reciclar o produto.

Assim, o upcycling tem como conceito estender o ciclo de vida de algum produto que está sendo descartado. Peças de roupas, acessórios e produtos em geral têm seu ciclo de vida alongado em novas funções e formatos, contribuindo para um estilo de vida mais sustentável.

Segundo a jornalista especializada em meio ambiente e sustentabilidade, Andréa Vialli, em matéria publicada em sua coluna na versão online do jornal Estadão, "upcycling é o termo usado para a reinserção, nos processos produtivos, de materiais que teriam como único destino o lixo, para criar novos produtos. É transformar algo que está no fim de sua vida útil em algo novo, de maior valor, sem precisar passar pelos processos físicos ou químicos da reciclagem. O material é usado tal como ele é.”.

O upcycling se tornou uma expressiva alternativa sustentável na área da moda. Segundo informações apresentadas na mesma matéria, na cidade de Londres, existem pontos de coleta de roupas e sapatos, lado a lado com os contêineres para lixo reciclado. São empresas que coletam essas peças para reinseri-las no processo produtivo novamente, e apenas $10 \%$ destas acabam tendo o lixo como destino final.

Pode-se observar alguns casos de upcycling inseridos em grandes marcas. Um exemplo é a parceria entre a marca inglesa From Somewhere e a australiana Speedo, que criou um vestido de festa a partir de retalhos de maiôs estocados da marca esportiva, conforme Figura 1, a seguir: 
Figura 1 : vestido de festa a partir de retalho.

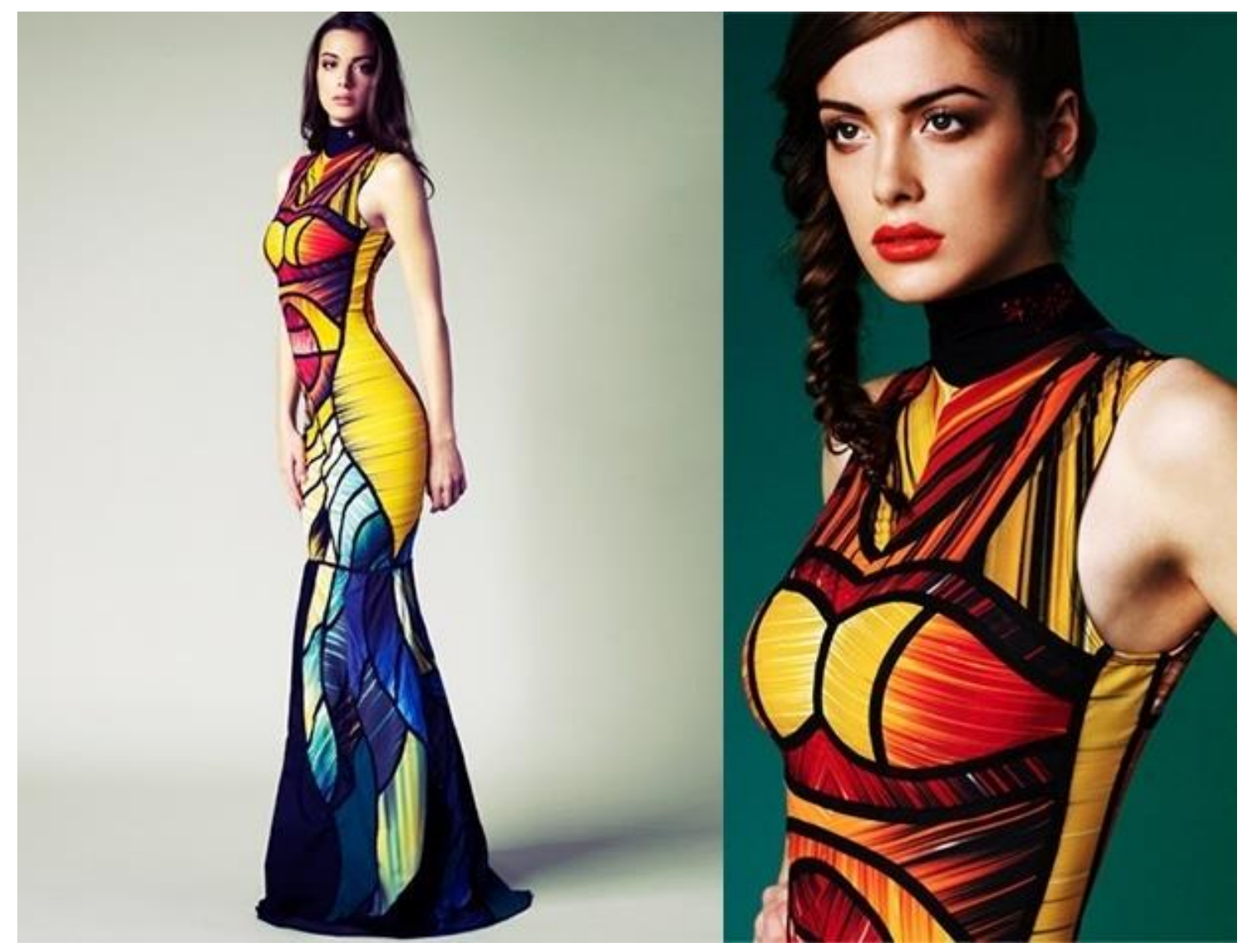

ECOTECE.ORG.BR

Outro exemplo da aplicação do upcycling na moda é a grife Vitrô, da designer Luana Ouverney, na qual mistura sustentabilidade e peças vintage. Sua marca possui três linhas: retrofit, vintage e eco-line. A linha vintage, como o próprio nome diz, é composta por peças vintage garimpadas em brechós, para serem usadas da forma como estão. A linha eco-line traz camisetas produzidas com malha de fibra de PET reciclado e estampa em tinta à base d'água. Já na linha retrofit é aplicado o upcycling, por meio do reaproveitamento de tecidos de ponta de estoque e peças de roupa de brechó, desmontadas e refeitas com novas modelagens, acabamento e detalhe, tornandose peças exclusivas.

\section{UM MODELO DE ESTRATÉGIA PRODUTIVA: O RESULTADO DO ESTUDO}

Como resultado deste estudo, gerou-se um modelo de estratégia produtiva, cujo fluxograma é apresentado no Anexo A deste trabalho. Visa-se utilizar do redesign de 
roupas de brechó como ferramenta de criação de produtos de moda sem perder a originalidade na produção industrial, ainda que em pequena escala.

Para que os modelos possam ser reproduzidas como em uma coleção sazonal, feita na indústria comum, o desenvolvimento deve ocorrer por meio da criação de uma peça piloto. O custo das peças não serão irrisórios como encontrados em brechós, pois passarão por um novo processo de desenvolvimento e produção. No entanto, os produtos serão mais acessíveis, diferentemente da maioria das peças exclusivas disponíveis no mercado.

Recomenda-se que cada peça esteja acompanhada de um TAG feito de papel reciclado, explicando como os produtos são concebidos, e ressaltando a importância do consumo consciente.

É importante enfatizar que por meio da pesquisa de público realizada, foi possível confirmar que existe essa demanda por peças de vestuário de caráter exclusivo, e que com estas peças o consumidor cria um vínculo maior do que o criado com peças produzidas em grande escala industrial.

Por isso, o uso de peças com grande variedade nos brechós será o princípio da criação para viabilizar a reprodução, etapa que será posterior, na qual, os materiais podem variar na cor, estampa e até mesmo textura, desde que se adapte ao caimento do modelo desenvolvido. Logo, mesmo na reprodução da peça piloto, os modelos não perderão a exclusividade. $\mathrm{O}$ resultado final dos produtos reproduzidos, do ponto de vista formal, será o mesmo, mas como um todo será sempre diferente e exclusivo.

Já sobre os sistema de produção, de acordo com Rabelo é ele que praticamente determina toda a filosofia de produção de uma empresa, assim como o layout dos recursos de produção, as estratégias de uso de meios, as políticas de estoques, o dimensionamento dos lotes, os tipos de equipamentos, os tipos de flexibilidade suportados e, entre outros, os parâmetros de avaliação a serem adotados.

Sendo assim, entendeu-se que o sistema de produção por encomenda, conhecido também como "orientada ao processo", "centrada no processo", "orientada à tarefa", "produção inconstante" e "controlada pela encomenda" é o que possui as características que se encaixariam com as propostas deste modelo, o qual visa trabalhar com pequenos lotes, e variedade de produtos produzidos sob encomenda, tendo continuidade conforme demanda. 
De acordo com o mesmo autor, este sistema é indicado para indústrias que produzem pequena ou média quantidade de uma gama relativamente grande de produtos. Neste contexto, após o desenvolvimento da coleção, as peças piloto serão reproduzidas em grades $\mathrm{P}, \mathrm{M}$ e $\mathrm{G}$, com 5 peças de cada tamanho, por modelo, à pronta entrega, tendo continuidade conforme demanda.

\section{CONSIDERAÇÕES FINAIS}

O modelo apresentado, objetiva mesmo que, numa pequena parcela, contribuir com o meio ambiente de forma criativa e inovadora. Por meio do redesign de roupas de brechó, as peças descartadas e desvalorizadas por se encontrarem fora das tendências de moda poderão passar por um processo de upcycling, estendendo seu ciclo de vida útil e voltando a ter valor estético e de mercado, ou seja, voltará a ser comercializada como um produto novo, de novo.

O diferencial deve-se ao fato de que ela pode ser reproduzida, mas sempre utilizando materiais oriundos de roupas descartadas em brechós ou de bazares beneficentes, de forma que, mesmo sendo reproduzidas não perderão a exclusividade, uma vez que os materiais dificilmente se repetirão.

Além disso, devido ao menor gasto com matérias-primas, o custo da peça será menor, sendo que o maior valor será gerado quase exclusivamente pela mão de obra e pelo processo de desenvolvimento de cada modelo

Esta proposta tem princípios sustentáveis, emocionais e busca ser economicamente acessível. Desta forma, a sustentabilidade está intrínseca neste processo, pois as roupas descartadas serão reutilizadas na criação de novas peças que serão redesenhadas, buscando um aspecto atual, mas sem usar novos materiais. Ao reutilizar materiais têxteis, os processos industriais pelos quais os tecidos passam e geram poluição, não farão parte deste cenário.

Leva-se em conta também o fato de que as peças de brechó têm valor emocional devido à história que cada uma pode carregar consigo, sem mencionar o fato de que peças com caráter exclusivo geram um vínculo com o usuário. O redesign de roupas de brechó pode ser visto como uma ligação emocional entre o que já foi moda e pode voltar a ser. 
As alternativas voltadas à gestão ambiental de produtos conforme Silva e Santos se dividem em dois diferentes aspectos: foco no produto, por meio do redesign ou ecodesign, e foco na análise do ciclo de vida do produto (ACV), ambos contemplados neste modelo.

Portanto, infere-se que a proposta de modelo aqui apresentada, é uma contribuição do design que pode influenciar nas escolhas do consumidor, o direcionando para a sustentabilidade. E no que tange às necessidades do mercado e do público que valoriza este tipo de produto, acredita-se que serão atendidas, tanto pelos valores objetivos (preço, conforto, o fato de não gerar impacto no meio ambiente, entre outros) quanto pelos subjetivos (como valor emocional, originalidade).

Artigo recebido em Outubro de 2015. Aprovado em Dezembro de 2015

DOI:http://dx.doi.org/105965/1982615×09012015024

\section{REFERÊNCIAS}

\section{Livros}

LIPOVETSKY, Gilles. O império do efêmero: a moda e seu destino nas sociedades modernas. São Paulo: Companhia das letras, 1989, p.347.

LIPOVETSKY, G.; SERROY, J. A cultura-mundo: resposta a uma sociedade desorientada. Tradução: Maria L. Machado. São Paulo: Companhia das Letras, 2011, p. 207.

ERNER, Guillaume. Vitimas da moda? como a criamos, por que a seguimos. São Paulo: Senac, 2005, p.256.

STONE, E. The dynamics of fashion. $3^{a}$. ed. New York: fairchild books, 2008, p.617.

BREZET, JC; ROCHA, C. Towards a model for product-oriented environmental management systems. In J. Charter \& U. Tischner (Eds.), Sustainable solutions: developing products and services for the future Sheffield: Greenleaf Publishing, 2001, pp. 243-262. 


\section{Artigos}

BEZERRA, G.M.F; MATOS, C.K.; PESSOA, J.B.G. “O consumo no futuro”. Anais do $7^{\text {}}$. Colóquio de Moda, Paraná, 2011, p.7.

NETO, G.; SOUZA, L.; SCAPINELLO, L. "Reflexões sobre a sustentabilidade no segmento de moda". Anais do $6^{\circ}$ Colóquio de moda, 2010, p.10.

CARNEIRO, R.M.S.; FLORES, A. R.B.; QUEVEDO, S.; ULBRITCHT, V.; VANZIN, T. "O novo consumidor na sociedade do conhecimento". Anais do $2^{\circ}$ Simpósio brasileiro de design sustentável, São Paulo, 2009, p.7.

GIURATTI, L. P.; BERTON, T. J. B.; PINHEIRO, N. "Revival e diferenciação como diretrizes da moda contemporânea: a elaboração de produtos de moda a partir da reciclagem de roupas de brechó". Anais do $7^{\circ}$. Colóquio de moda, Paraná, 2011 p.7.

ANICET, A.; BESSA, P.; BROEGA, C. "Design de superfícies a partir de resíduos industriais têxteis". Anais do 3o Simpósio Brasileiro e Internacional de Design Sustentável. Pernambuco, 2011, p.7.

SILVA, J. S. G.; SANTOS. A., 2009. "Implicações dos conceitos da sustentabilidade no design: uma revisão crítica”. Revista tecnologia e sociedade, n. 08, Paraná, p.14.

\section{Sites}

Ministério do Desenvolvimento, Indústria e Comércio Exterior. Cadeia Produtiva Têxtil e de Confecções,2012.DistritoFederal.http://www.desenvolvimento.gov.br/sitio/interna/inter na.php?area $=2 \&$ menu=3696> . Acesso em 05 de maio de 2013. 
LIVNI, A; SCUDER, F. Manifesto moda lenta. 2010. < http://analivni.com/AnaLivniMODAlenta-SLOWfashion/filosofia.html>. Acesso em 04 de maio de 2013.

CARTER, Kate.,2008. Why fast fashion is so last season. Disponível em : http://www.theguardian.com/lifeandstyle/2008/jul/23/ethicalfashion.fashion_. Acesso on line em 10-09-2014.

MARTINS, S. B.; SAMPAIO, C. P.; MELLO, N. C., 2011. "Moda e sustentabilidade: proposta de sistema produto-serviço para setor de vestuário. projética revista científica de design". Universidade Estadual de Londrina, v.2, n.1, junho, p.p:126-139. disponível em: $\quad<$ http://www.uel.br/revistas/uel/index.php/projetica/article/view/10532/9259> acesso online em 05 de maio de 2013.

Ecotece.org.. 2012. Retalhos de maiôs viram vestido de festa. $<$ http://ecotece.org.br/blog/tag/upcycle/ $\geq$. acesso em 6 de maio de 2013.

RABELO, Ricardo, 2012. “A definição dos indicadores de desempenho e os sistemas de produção".<http://www.das.ufsc.br/ rabelo/ensino/das5313/materialdas5313/modulo1/in dicadores_de_desempenho/tipos-sistemas.pdf $>$. acesso em 20 de abril de 2013. 


\section{ANEXO A}

“FLUXOGRAMA DO SISTEMA PRODUTIVO PROPOSTO”. FONTE:

PRÓPRIA

\section{FLUXOGRAMA D0 SISTEMA PRODUTIVO PROPOST0}

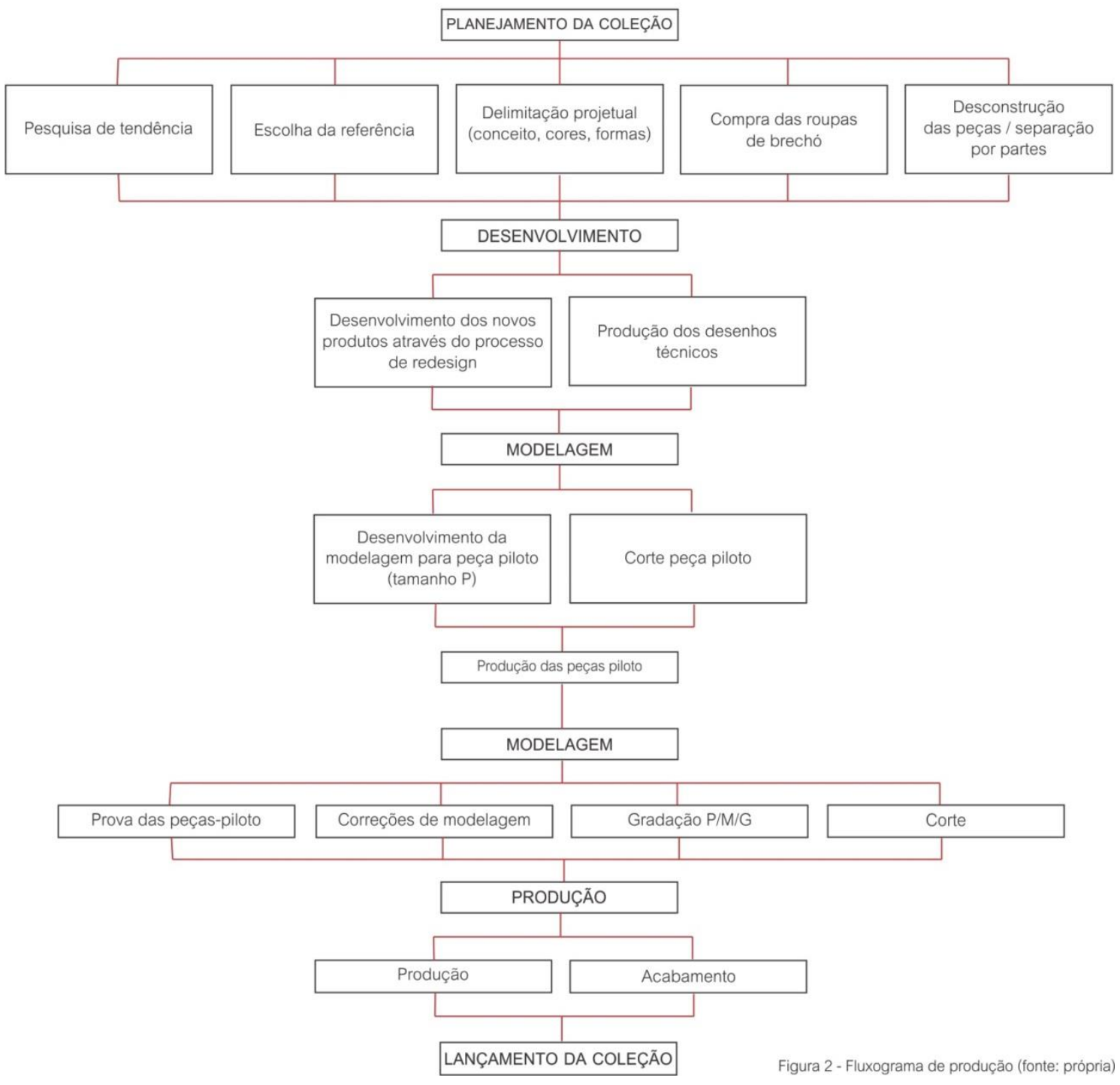

